\title{
sciendo
}

\section{What is the quality of life in Romania compared to other EU countries?}

\author{
Cristina BOBOC \\ Bucharest University of Economic Studies, Bucharest, Romania \\ cristina.boboc@csie.ase.ro \\ Simona-Ioana GHITĂ \\ Bucharest University of Economic Studies, Bucharest, Romania \\ simona.ghita@csie.ase.ro \\ Adelina POPESCU \\ Bucharest University of Economic Studies, Bucharest, Romania \\ Andreea-Simona SĂSEANU \\ Bucharest University of Economic Studies, Bucharest, Romania \\ andreea.saseanu@com.ase.ro
}

\begin{abstract}
Quality of life is a broad multidimensional concept that usually includes both objective and subjective evaluations of positive and negative aspects of life.

This paper analyzes the interdependencies between the nine dimensions of quality of life in EU countries, based on objective indicators according to EUROSTAT approach.

The main objective of this paper is to identify some patterns among EU countries and some directions of improvement of quality of life in Romania by using correlation analysis, principal component analysis and cluster methods. There are identified three main dimensions of quality of life: Material dimension, Social dimension and Educational and environmental dimension. Moreover there are identified three clusters among EU countries: one with high levels of all dimensions, one with high levels of Material dimension but low levels of Social dimension and the third one with low levels of Material dimension and Educational and environmental dimension. Romania is included in the third cluster with a high level on Social dimension but a low level in Material dimension and Educational and environmental dimension.
\end{abstract}

Keywords: quality of life, Romania, EU, comparative study,

\section{Introduction}

Since antiquity philosophers have been preoccupied with defining the main aspects of a "good life", but without reaching a common definition. Research on quality of life has identified many aspects, some of which are intangible and difficult to evaluate (Stiglitz et al., 2009). The second half of the 20th century marks a move of the center of interest in the study of quality of life from quantitative to qualitative aspects, amid intensive development of science and information. At the same time, researches in the field combine the economic and social dimension (Massam, 2002; Andrasko, 2013).

Life quality should be analyzed on a multidimensional framework. Quality of life 
indicators are both subjective (such as personal satisfaction) and objective (such as income), but these two perceptions combined determine the welfare of an individual, demonstrating that the information provided by the two types of indicators are complementary. EUROSTAT quantifies the multiple dimensions of quality of life by using objective indicators, on nine dimensions: material-living conditions, productive or main activity, health, education, leisure and social interaction, economic and physical safety, governance and basic rights, natural and living environment, overall experience of life.

This paper is a comparative analysis between EU countries in terms of quality of life, based on the dimensions defined by EUROSTAT, by choosing one relevant indicator for each dimension for the last year available (for most of them the reference year was 2017). The descriptive analysis of each dimension is followed by a correlation analysis between all the dimensions of quality of life. As long as it was observed a significant correlation between them, the principal component analysis is performed in order to identify some noncorrelated dimensions. Moreover, to describe some patterns among EU countries, by using a cluster analysis there are identified three homogenous clusters: one with high levels of all dimensions, one with high levels of Material dimension but low levels of Social dimension and the third one with low levels of Material dimension and Educational and environmental dimension. Finally, the paper proposes some directions of improvement for the quality of life in Romania.

\section{Literature review}

Over time, in order to quantify the economic activity results, the development level and the progress, the GDP and its growth rate were widely used. But this indicator has expanded its usefulness and significance, being even used as an estimator of population well-being (Pantisano et al., 2014). However, a number of limitations on the use of GDP have been identified in the assessment of the quality of life aspects, among which the fact that it does not include all non-material, non-economic, non-marketable aspects related to environment and its services provided to the society.

Thus, a series of "beyond GDP" initiatives have been launched to correct these limitations and to integrate the range of measures designed to assess the quality of life.

In this regard, Commission on the Measurement of Economic Performance and Social Progress run by Joseph Stiglitz, Amartya Sen and Jean Paul Fitoussi has produced a series of 12 recommendations to optimize the society "well-being" quantification, focusing on the multidimensionality of the concept of quality of life, grouped in 3 directions: Material-living conditions, Quality of Life and Sustainability. Thus, recommendations based on material living conditions include: the need to consider income and consumption from the households' perspective, in order to assess the material well-being; the need to consider the income, consumption and wealth distribution, including income from non-market activities. The second group of recommendations aims to include non-material aspects in the assessment of the quality of life and to improve the quantification methods: health, education, personal and environmental activities, including the identification and assessment of inequalities, as well as the combination of objective and subjective aspects of well-being. Environmental recommendations aim at: identifying indicators to assess the economic aspects of sustainability, including a monetary sustainability index, and physical indicators pointing some alert situations that can lead to environmental damage (Eurostat, 2017). 
A number of researchers have addressed the quality of life in terms of social indicators. Thus, in 1972, Flax proposed a list of 14 indicators, aimed at measuring the quality of life in urban areas, covering the demographic sphere, participation in the labor market, income, mental health, crime, life cost, political life, education, environmental quality (Flax, 1972).

Other researchers included, besides the levels of indicators, dynamics indicators as well, to capture evolution, changes over time (Schneider, 1976), while others focused more on mental health indicators and reflected contextual aspects that affect mental health: economic context, family life and ethnic status (Bloom, 1975; Tyron, 1967).

Social indicators have been included in a wide range of models in an attempt to estimate the quality of life as a whole or various components. Most often, additive models were used, where the overall level of well-being was determined as a weighted average of the quality of life components (Zautra \& Goodhart, 1979). The authors pointed out that the main limitations of the social indicators used in the measurement of the quality of life were: the high degree of uncertainty, the low degree of application of some indicators that measure aspects that characterize a small number of people.

Another direction in developing methods of assessing the quality of life is the objective / subjective ratio. Some researchers have focused on assessing Quality of Life based on objective issues, starting from the physical resources needed to meet life goals or human needs (Erikson, 1993; Uusitalo, 1994). The aspects considered by applying the indicators were: population structure, income distribution, employment, literacy, and economic activity outcomes.

Other researchers have emphasized the subjective aspects of the quality of life, the measurement of happiness (Cambell et al., 1976, Easterlin, 2003). Amartya Sen (2003) proposed an unification, a combination of the two points of view: objective and subjective. (Sen, 2003).

Another "dispute" in the development of viable tools used to measure the multiple facets of quality of life addresses the level, the extent to which well-being is manifested: individual or collective, societal. According to Lane (1996) the quality of life has an individual dimension, as it has to reflect the quality of the individual. However, as the individual does not live isolated, but interacts with people, the way he acts is interdependent with the society in which he lives. Thus, Veenhoven (2006) stated that the quality of life in the urban environment is related to ensuring the sustainability of the activities and the environment.

Among the most important initiatives to optimize the quality of life indicators system, we mention the United Nations initiative (1994), which proposed that these indicators have to address, to signal some deficiencies, some problems that need to be solved. Flynn (2000) shows the need to quantify the impact of information technology, of modern methods on quality of life (Calvert-Henderson Quality of Life indicators). This indicators system covers 12 socio-economic areas (including education, employment, energy, environment, health, human rights, income, infrastructure, national security, public safety). (Pantisano, 2014). Other initiatives include the development of a composite well-being index, on the OECD's proposal and with the effective participation and involvement of citizens. OECD Better Life Index is consistent with the multidimensionality of the quality of life concept, covering the following areas: housing, income, jobs, community, education, environment, health, life satisfaction, safety and work-life balance. The Index of Economic Well-Being, developed in 1998 , focuses on the idea that inequalities of different types can have an impact on quality of 
life, so it includes this, together with other three areas: consumption-flows, wealth and economic security. Within the European System of Social Indicators, the Index of Individual Living Conditions is a composite index calculated based on 7 sub-indices: income/standard of living, housing, housing area, education, health, social-relations, work. EUROSTAT quantifies the multiple dimensions of quality of life using objective indicators, grouped into 9 sub-domains: material-living conditions, productive or main activity, health, education, leisure and social interaction, economic and physical safety, Governance and basic rights, natural and living environment, overall experience of life. This EUROSTAT approach is used in the present paper.

\section{Methodology}

The field of quality of life addresses issues related to both objective factors and subjective perceptions of quality of life. In the literature there are numerous contributions, highlighting the link between education, employment, welfare and life satisfaction. For example, Blanchflower and Oswald (2004) analyzes welfare as the support of quality of life, Ferrante (2009) explains the connection between education and life satisfaction, Kapteyn, Smith and Soest (2009) highlight the determinants of life satisfaction, considering that it is based on four pillars, namely job or daily activities, social contacts and family, health and income. Therefore, in our analysis we have included 9 different variables to explain quality of life on the nine quality of life dimensions taken into account by EUROSTAT in their measure of quality of life.

In this paper we have used multidimensional methods (principal component analysis, cluster analysis and correlation analysis) to analyze the interdependencies between the different dimensions of quality of life, to identify the typologies of countries in EU and to estimate the impact of each group of factors on the quality of life index.

All the data used in this paper are from EUROSTAT databases for all EU countries and for the year 2017 (or the latest year available).

\section{Results and discussions}

The main objective of this paper is to determine the interdependencies between the dimensions of quality of life:

- Living conditions. In order to describe the living conditions it is analyzed the indicator for material deprivation, defined as the inability to afford a set of predefined material items that are considered by most people to be desirable or even necessary to experience an adequate quality of life. In 2017, more than $16.9 \%$ of the EU-28 population could not afford three or more out of nine standard deprivation items, while $6.6 \%$ could not afford four or more items (severe material deprivation). The highest rates of material deprivation are recorded in Bulgaria (30\%), Greece $(21.1 \%)$ and Romania (19.4\%) while the lowest levels are registered in countries such as Finland, Sweden, Luxembourg and the Netherlands, between $2-3 \%$.

- Employment. Work affects the quality of life not only because of the income it generates but also because of the role it plays in people's lives, giving them the sense 
of identity, opportunities to socialize with others, opportunities to be creative and learn new things. In this paper it is used the employment rate to explain the employment dimension. The EU Member States with the highest employment rates are Sweden (81.8\%), Germany (79.2\%), Estonia (78.7\%), the Czech Republic (78.5\%) and England (78.2\%). As far as Romania is concerned, it is below the European Union average (72.51\%), with $68.8 \%$, followed by Belgium, Spain, Croatia, Italy and Greece.

- Health. Studies have shown that health and workplace are the main factors influencing the quality of life of a person. The health of an individual has an invaluable value because a good state of health allows a person to actively participate in the labor market and to have a social life. Life expectancy at birth is considered one of the most relevant indicators to compare the health status of different countries. It expresses the average number of years a person can live, while the death rate remains constant in the future. In Romania life expectancy at birth had an upward trend, from 72 years in 2006 to 75 years in 2017.

- Education is the main engine of technological innovation. People with a solid education are healthier, more active and involved in social life, have higher incomes and definitely have higher quality of life. Skills shortage limits the access to employment, increases the risk of poverty and hinders the prosperity of a country. One of the educational indicators considered by Organization for Economic Cooperation and Development (OECD) is the share of the population aged between 25 and 64 years who have graduated a higher educational institution. In 2017, compared with 2010, the percentage of the population graduating from the faculty increased in all EU countries. The highest increase was recorded in Austria, 13.5\%, from 16.2\% in 2010 to 29.7 in 2017. As far as Romania is concerned, the percentage is quite small, only $3.4 \%$, this being a consequence of the fact that indicators such as poverty, material deprivation, have alarming values.

- Social Relations. As long as humans are social beings, their perception of welfare is closely linked to their interactions and social relationships. Those who are surrounded by friends, spend a lot of time with family, participate in different cultural and social events are undoubtedly much happier. Participating in cultural or sports activities is an important indicator of social relationships. In developed countries such as Sweden, Holland, Denmark, Finland, Luxembourg and France, the percentage of the population participating in various activities is over $80 \%$, while in Romania and Bulgaria, a very low percentage, under $32 \%$ participate in various cultural activities or sports.

- Safety. A variety of risks may threaten the material conditions and safety of individuals and households. In this paper, we will analyze data on economic safety in terms of the inability of individuals to face unexpected financial expenses. In 2017, more than half of the population of eight EU countries reported that they are unable to cope with unforeseen financial costs: Latvia, 59.9\%, Croatia (56.2\%), Bulgaria (53.2\%), Greece (52.7\%) and Romania (52.5\%). The highest fall in this indicator was in Hungary, from $73.9 \%$ to $31.5 \%$. In Greece, however, this percentage increased 
significantly from $28.2 \%$ to $52.7 \%$. Neither Romania has had a positive influence on this indicator, the percentage of Romanians who cannot cope with unexpected financial expenses increased by 7.7\% from 2010 until 2017.

- Governance. Trust in the political system is the trust of citizens in the actions of a Government that does what is right for society. This is essential for cohesion and social well-being. The Romanians' confidence in the Government is 4.8, exceeding the average of this indicator in the European Union (3.8). Higher levels of trust are found in countries such as Finland, Denmark, Malta, the Netherlands, with rates more than 5 and the lowest rates of trust in governance are recorded in countries such as Portugal, Slovenia, Spain (under 2).

- Environment. Although in the first instance the environment does not seem to influence so much the quality of life, such as material living conditions, it still has multiple influences on human health and therefore on quality of life. The most significant decrease of the percentage of people exposed to pollution occurred in Malta, 14.3\%, but there are countries where this percentage increased in 2017 compared to 2010. For example Germany ( $+3.4 \%$ ), Lithuania $(+2,9 \%)$, Luxembourg $(+6.5 \%)$, while in Romania the percentage of the population exposed to pollution dropped from 2010 in 2017, from $19.9 \%$ to $14.6 \%$.

- Overall satisfaction. Subjective welfare shows how people evaluate their own lives. Countries with a high standard of living have a high quality of life satisfaction: Denmark, Finland, Sweden, the Netherlands. The opposite is Bulgaria with a very low life satisfaction. Romania ranks 14th, with a satisfaction rate of 7.1 equal to France's satisfaction rate, for example. The last year for which this indicator was calculated is 2013.

Analyzing the position of Romania reported at the level of the European Union regarding all nine indicators of the quality of life, we can state that in Romania the quality of life level is modest. The most affected indicator refers to material living conditions, with Romanians facing many problems in meeting the fundamental needs. In terms of low living conditions, Romania ranks third in the European Union in 2017, being at a considerable distance from developed countries such as Sweden, Finland, Luxembourg, countries where a very low percentage of the population is facing with problems in meeting basic needs. However, with regard to the general quality of life index, Romania recorded a significant evolution from 25.52 in 2012 to 140.31 in 2019. The rising trend was not maintained throughout the whole period 2012-2019, in 2017 recording a decline from 146, 13 to 143.04 compared with 2016 and from 144.05 in 2018 to 140.31 in 2019 (Figure 1). 

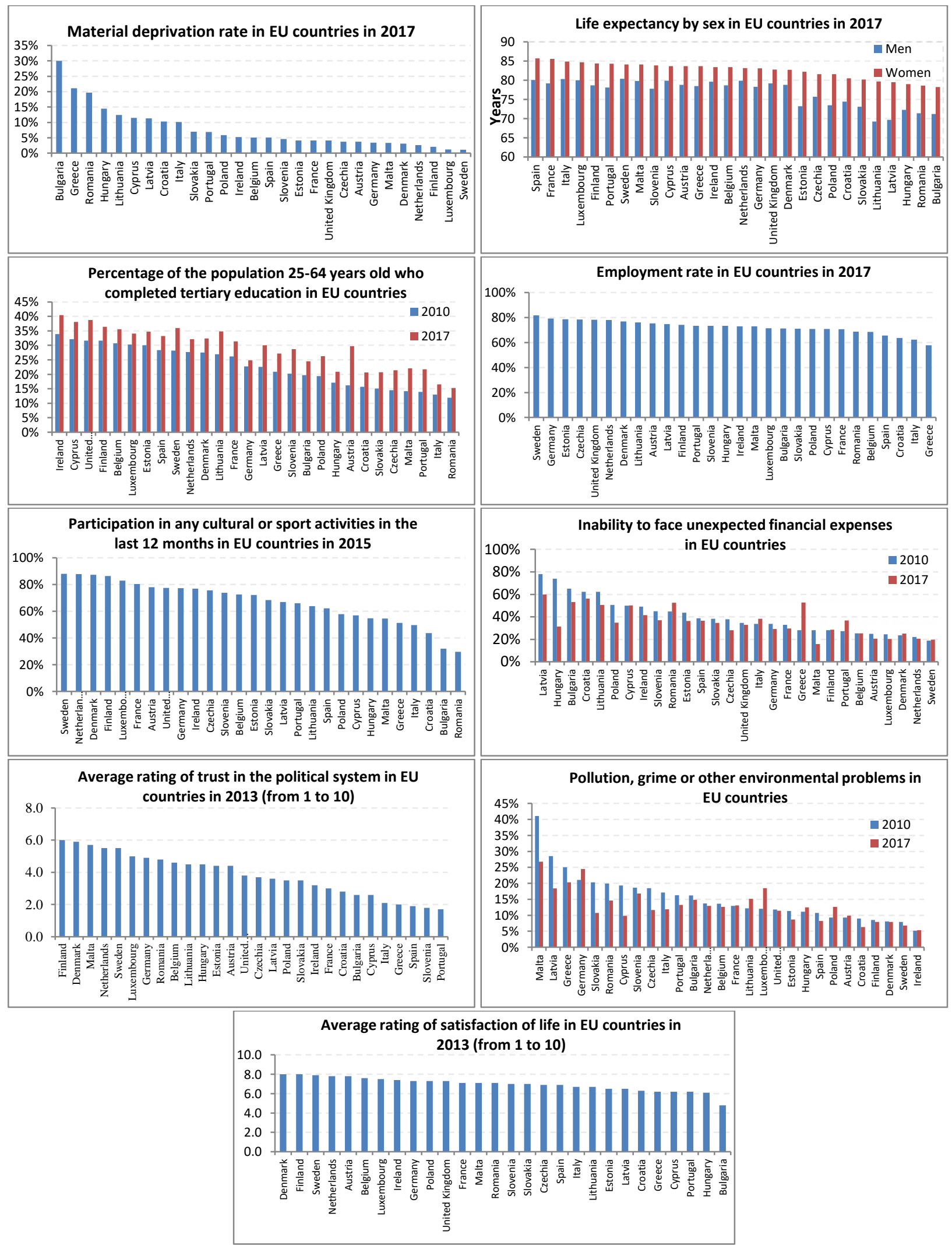

Figure 1. Indicators for the 9 quality of life dimensions and Quality of life index

Source: Own computations based on EUROSTAT data 
In order to analyze the interdependencies between all the dimensions of quality of life, we have used firstly a correlation analysis. It could be observed that all the dimensions are significantly interrelated between them, except the percentage of people exposed to pollution. Therefore, principal component analysis (PCA) is used to reduce the complexity of the data and to present the information on fewer dimensions. It is mathematically defined as an orthogonal linear transformation that projects the data to a new coordinate system (which is made by principal components) in order to obtain the greatest variance explained by this projection of the data (Table 1).

Table 1. Correlation matrix (Pearson correlation and significant levels)

\begin{tabular}{|c|c|c|c|c|c|c|c|c|c|}
\hline & $\begin{array}{c}\text { Material } \\
\text { deprivation } \\
\text { rate }\end{array}$ & $\begin{array}{l}\text { Employmen } \\
\text { t rate }\end{array}$ & $\begin{array}{l}\text { Population } \\
\text { with tertiar } \\
\text { y education }\end{array}$ & $\begin{array}{c}\text { Life } \\
\text { expectanc } \\
y\end{array}$ & Social life & $\begin{array}{c}\text { Inability to } \\
\text { face } \\
\text { unexpecte } \\
\text { d financial } \\
\text { expenses }\end{array}$ & $\begin{array}{c}\text { Trust in } \\
\text { the } \\
\text { political } \\
\text { system }\end{array}$ & $\begin{array}{c}\text { Pollutio } \\
\mathbf{n}\end{array}$ & $\begin{array}{c}\text { Life } \\
\text { satisfatio } \\
\mathbf{n}\end{array}$ \\
\hline $\begin{array}{l}\text { Material } \\
\text { deprivation rate }\end{array}$ & & -0.496 & -0.377 & -0.682 & -0.834 & 0.787 & -0.357 & 0.220 & -0.800 \\
\hline Employment rate & 0.004 & & 0.400 & 0.096 & 0.744 & -0.526 & 0.678 & -0.242 & 0.599 \\
\hline $\begin{array}{l}\text { Population } \\
\text { with tertiary } \\
\text { education }\end{array}$ & 0.024 & 0.017 & & 0.298 & 0.569 & -0.204 & 0.322 & -0.390 & 0.322 \\
\hline Life expectancy & 0.000 & 0.313 & 0.062 & & 0.439 & -0.683 & 0.128 & 0.011 & 0.431 \\
\hline Social life & 0.000 & 0.000 & 0.001 & 0.010 & & -0.635 & 0.510 & -0.346 & 0.736 \\
\hline $\begin{array}{l}\text { Inability to face } \\
\text { unexpected } \\
\text { financial expenses }\end{array}$ & 0.000 & 0.002 & 0.149 & 0.000 & 0.000 & & -0.512 & -0.083 & -0.742 \\
\hline $\begin{array}{l}\text { Trust in the } \\
\text { political system }\end{array}$ & 0.031 & 0.000 & 0.047 & 0.258 & 0.003 & 0.003 & & -0.204 & 0.714 \\
\hline Pollution & 0.130 & 0.107 & 0.020 & 0.477 & 0.036 & 0.337 & 0.149 & & .130 \\
\hline Life satisfaction & 0.000 & 0.000 & 0.048 & 0.011 & 0.000 & 0.000 & 0.000 & -0.221 & \\
\hline
\end{tabular}

Source: Authors' own research.

By applying this method, the projection of data on the first three principal components preserves $82.13 \%$ of the total inertia (32\% for the first axis and $31.52 \%$ for the second axis) (Table 2).

Table 2. Total variance explained

\begin{tabular}{|c|c|c|c|c|c|c|}
\hline \multirow{2}{*}{ Component } & \multicolumn{3}{|c|}{ Initial Eigenvalues } & \multicolumn{2}{c|}{ Rotation Sums of Squared Loadings } \\
\cline { 2 - 7 } & Eigenvalues & $\begin{array}{c}\text { \% of Variance } \\
\text { explained }\end{array}$ & $\begin{array}{c}\text { Cumulative } \\
\text { variance } \\
\text { explained }\end{array}$ & Eigenvalues & $\begin{array}{c}\text { \% of Variance } \\
\text { explained }\end{array}$ & $\begin{array}{c}\text { Cumulative } \\
\text { variance } \\
\text { explained }\end{array}$ \\
\hline 1 & 4.864 & 54.046 & 54.046 & 2.884 & 32.049 & 32.049 \\
\hline 2 & 1.458 & 16.203 & 70.249 & 2.837 & 31.519 & 63.568 \\
\hline & 1.069 & 11.882 & 82.131 & 1.671 & 18.563 & 82.131 \\
\hline
\end{tabular}

Source: Authors' own computations for PCA method, based on Eurostat data

On the first axis, the best represented variables on positive side are: Life satisfaction, Trust in Political System, Social Life and Employment rate. As long as these variables are 
mainly related to social aspects of quality of life, we will call this component Social Dimension (Table 3).

On the second axis, the best represented variables on negative side are: Material deprivation rate and Inability to face unexpected financial expenses. As long as these variables are mainly related to material aspects of quality of life, we will call this component Material Dimension.

On the third axis, the best represented variable on positive side is Population with tertiary education and on negative side is Pollution. We will call this component Educational and environmental Dimension.

Table 3. Rotated component matrix

\begin{tabular}{|c|c|c|c|}
\hline & \multicolumn{3}{|c|}{ Component } \\
\hline & 1 & 2 & 3 \\
\hline Trust in the political system & 0.891 & 0.062 & 0.121 \\
\hline Employment rate & 0.845 & 0.145 & 0.254 \\
\hline Life satisfation & 0.725 & 0.539 & 0.125 \\
\hline Social life & 0.598 & 0.549 & 0.448 \\
\hline Life expectancy & -0.068 & 0.933 & 0.078 \\
\hline Material deprivation rate & -0.400 & -0.817 & -0.237 \\
\hline Inability to face unexpected financial expenses & -0.526 & -0.776 & 0.144 \\
\hline Pollution & -0.114 & 0.089 & -0.855 \\
\hline Population with tertiary education & 0.198 & 0.269 & 0.749 \\
\hline
\end{tabular}

Source: Authors' own computations for PCA method, based on Eurostat data

By applying Ward's method for hierarchical clustering on these data, it could be observed that EU countries could be clustered into 3 groups. Countries in first cluster and second cluster have high values for the Material Dimension, meaning that people from these countries do not have financial problems. These countries have a low rate of Material Deprivation and a low percentage of people unable to face unexpected financial expenses. Moreover, countries from the first cluster have high values of Social Dimension meaning that they trust in political systems from their countries, they have an employment and a social life and they are satisfied with their lives. Countries from the second cluster have lower values of Social Dimension. In the third cluster there are countries with low values of Material dimension, meaning that people from these countries have financial problems.

Romania is among the countries from the third cluster. It has among the lowest levels of Material Dimension and Educational and Environmental Dimension but with a high level on Social Dimension. According to OECD (2011) income and wealth are essential components of individual well-being. One important direction for improving the quality of life in Romania is the improvement of material living conditions, meaning increasing the income of the population and the ownership of material goods. Both income and wealth enhance individuals' freedom to choose the lives that they want to live.

Education enriches people's understanding of themselves and world. It raises people's productivity and creativity and promotes entrepreneurship and technological advances. It's the education which transforms a person to live a better life and leads to broad social benefits to individuals and society (Javed, 2016). As long as educational dimension in Romania is very low, improving educational level of the population will lead to a better quality of life. 

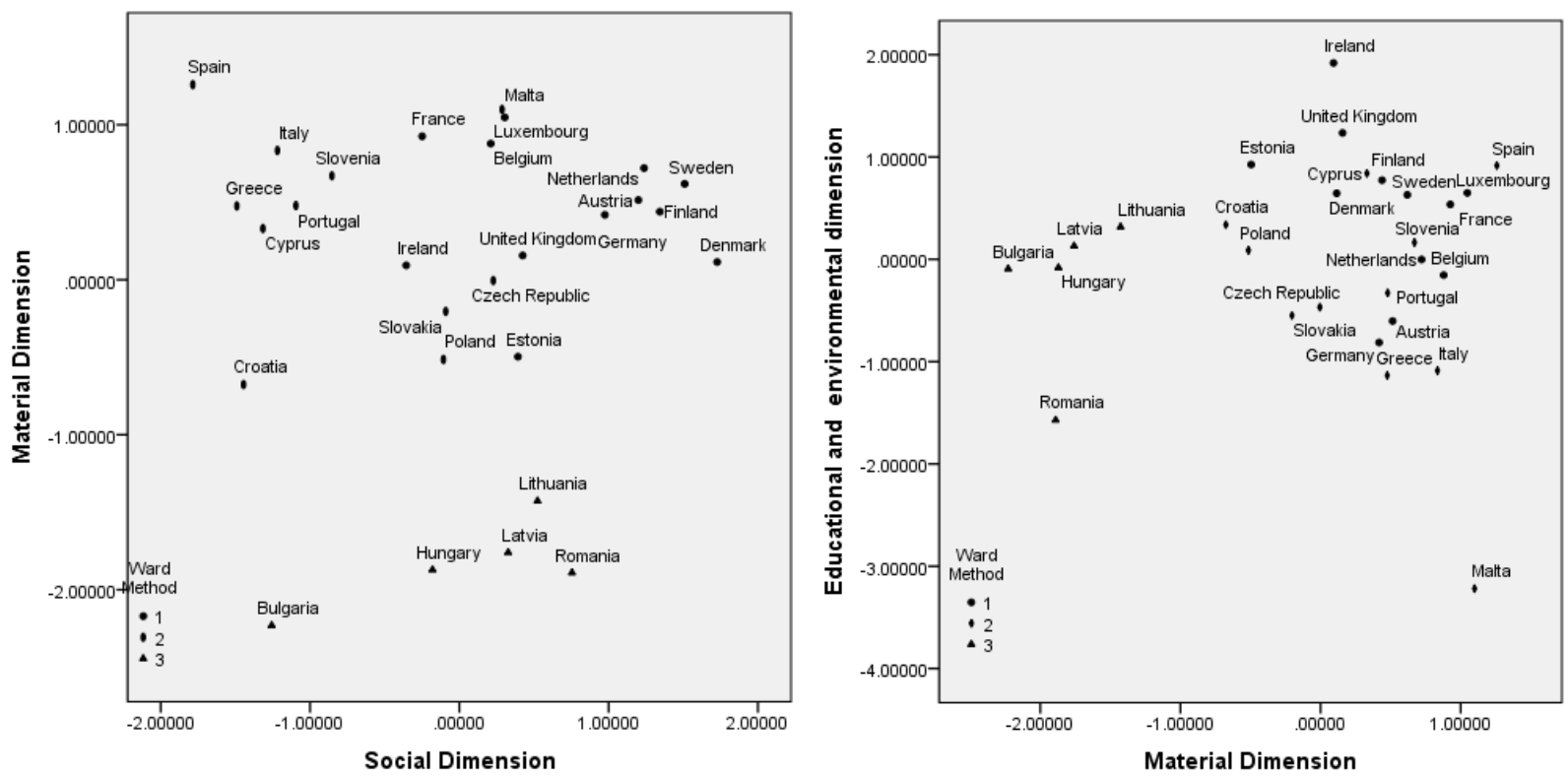

Figure 2. EU countries projected on the first three dimensions identified by PCA analysis Source: Own computations based on EUROSTAT data

Although the environment is usually discussed within the context of sustainability, it is equally important for an individual's quality of life. Environmental conditions affect human health and well-being directly, but also indirectly, by natural disasters or industrial accidents. A high-quality environment means basic aspects such as clean water and air but also intangible aspects such as noise-free residential and work environments or easy access to nature and green spaces. In Romania the environmental dimension is lower than in other EU countries, meaning that improving quality of life is not only improving material and educational dimension but also improving the natural environment of living.

\section{Conclusion}

Over time, the issue of quality of life has captured the attention of researchers in the field, but without reaching a unique definition of the concept. That is why there have been different approaches to life quality assessment, some based on economic aspects (for example, based on GDP and its growth rate), others on social issues (including physical and mental health, human rights, safety); some based on objectivity, others on subjectivity or both; some based predominantly on quantitative aspects, others on qualitative aspects; some consider that the quality of life must be analyzed at the individual level, others - that it has a collective, societal character.

The main objective of this paper is to determine the interdependencies between the dimensions of quality of life and to perform a comparative analysis between EU countries in terms of quality of life viewed from a multidimensional perspective. 9 dimensions have been considered, considering the EU approach on assessing the quality of life: Living conditions, employment, health, education, social relations, safety, Governance, environment and overall satisfaction. The values of the variables were provided by the EUROSTAT database, covering the year 2017, or the most recent year available.

Following the application of the Principal Component Analysis (PCA), the initial data set was 
reduced to 3 main components cumulating $82.13 \%$ of the total variability: social dimension, material dimension and educational-environmental dimension.

The hierarchical clustering method applied on European countries has lead to 3 clusters: countries in first and second cluster have high values for the Material Dimension, with a low share of people facing financial problems and with a low material deprivation rate.

The countries of the first two clusters have contradictory characteristics in terms of their social dimension: high values for the countries in the first cluster, compared to low values for the countries in the second cluster. Countries in the third cluster are characterized by low values of Material dimension, Romania being included in the last cluster, experiencing the lowest levels of Material Dimension and Educational - Environmental Dimension, but a high level of Social Dimension. Hence the main ways to improve the quality of life in Romania are: increasing the population income and educational level, improving the ownership of material goods, in order to enhance the individuals' freedom, the ownership and to encourage an increase in the labor productivity and innovation. Also, it is recommended to significantly improve the low environmental dimension, so that to obtain a cleaner natural environment of living.

\section{References}

Andráško. I. (2013). Quality of Life: An Introduction to the Concept, Masarykova univerzita Brno 2013, 15-20.

Blanchflower, D.G., \& Oswald, A.J. (2004). Well-being over time in Britain and the USA. Journal of Public Economics, 88, 1359 - 1386.

Bloom, B.L. (1975). Changing patterns of psychiatric care, New York: Human Sciences Press.

Campbell, A., Converse, P., \& Rodgers, W. (1976). The Quality of American Life. New York: Russell Sage Foundation.

Easterlin, R. (2003). Explaining Happiness. Proc. Natl. Acad. Sci., 100 (19), 11 176-11 183.

Erikson, R. (1993). Descriptions of Inequality: The Swedish Approach to Welfare Research. In: Nussbaum, M. , Sen, A. (Eds.). The Quality of Life (pp. 67-87). Oxford: Clarendon Press.

Eurostat (2017). Final report of the expert group on quality of life indicators, 2017 Edition. Eurostat, Statistical Reports. Retrieved from https://ec.europa.eu/eurostat/web/products-statistical-reports/-/KS-FT-17-004

Ferrante, F. (2009). Education, Aspirations and Life Satisfaction, Working Papers 2009-03, Universita' di Cassino, Dipartimento di Scienze Economiche.

Flax, M.J. (1972). A study in comparative urban indicators: Conditions in 18 large metropolitan areas, Washington D.C.: The Urban Institute.

Flynn, P., Lickerman, J., \& Henderson, H. (2000). Calvert-Henderson Quality of Life Indicators. Calvert Group, 392 pp.

Kapteyn, A., Smith, I. P., van Soest, A. H. O. (2009). Comparing Life Satisfaction. RAND Working Paper No. WR-623-1.

Lane, R. E. (1996). Quality of Life and Quality of Persons: A New Role for Government. In: Offer, A. (Eds.). Pursuit of the Quality of Life. (pp. 256-293). New York: Oxford University Press.

Massam, B. H. (2002). Quality of life: public planning and private living. Progress in Planning, 58, 141-227.

Pantisano, F., Craglia M., \& Rosales-Sanchez, C. (2014). New Indicators of Quality of Life: A Review of the Literature, Projects, and Applications. Citizen Science Observatory of New Indicators of Urban Sustainability (project 1076). Retrieved from https://www.rd-alliance.org/new-indicators-quality-life-review-literature-projectsand-applications.html 
Schneider, M. (1976). The "Quality of Life" and social indicators research, in Public Administration Review, 36, 297-305.

Sen, A. (1993). Capability and Well-Being. In: Nussbaum, M.C., Sen, A. (Eds.). The Quality of Life. (pp. 30-53). Oxford: Clarendon Press.

Stiglitz, J.E., Sen, A., \& Fitoussi, J.P. (2009). Report by the Commission on the Measurement of Economic Performance and Social Progress. Retrieved from https://ec.europa.eu/eurostat/documents/118025/118123/Fitoussi+Commission+ report

Tyron, R.C. (1967). Predicting group differences in cluster analysis: The social area problem, Multivariate Behavioral Research, 2, 453-475.

United Nations (1994). Information on Social Development Publications and Indicators in the United Nations System. Working Paper No. 7. New York: United Nations Publications

Uusitalo, H. (1994). Social Statistics and Social Reporting in the Nordic Countries. In: P. Flora, P., Kraus, F., Noll, H.-H., Rothenbacher, F. (Eds.). Social Statistics and Social Reporting in and for Europe (pp. 99-120). Bonn: Informationszentrum Sozialwissenschaften,.

Veenhoven, R., \& Hagerty, M. (2006). Rising Happiness in Nations, 1946-2004: A reply to Easterlin. Soc Indic Res, 79, 421-436.

Zautra, A. \& Goodhart D. (1979). Quality of Life Indicators, Community Mental Health Review, 4:1, 1-14. 